\title{
Increased airway responsiveness to acetaldehyde in asthmatic subjects with alcohol-induced bronchoconstriction
}

\author{
M. Fujimura*, S. Myou*, Y. Kamio ${ }^{+}$, Y. Ishiura*, K. Iwasa*, T. Hashimoto*, T. Matsuda*
}

\begin{abstract}
Increased airway responsiveness to acetaldehyde in asthmatic subjects with alcoholinduced bronchoconstriction. M. Fujimura, S. Myou, Y. Kamio, Y. Ishiura, K. Iwasa, T. Hashimoto, T. Matsuda. (C)ERS Journal Ltd 1999.

ABSTRACT: Bronchial responsiveness to acetaldehyde, a main factor in alcoholinduced bronchoconstriction, and methacholine were compared between 10 subjects with alcohol-induced bronchoconstriction and 16 asthmatic subjects without alcohol sensitivity.

In the alcohol-sensitive group, the geometric mean (geometric SEM (GSEM)) of the provocative concentration of methacholine (PC20,meth) and acetaldehyde (PC20,acet) causing a $20 \%$ fall in forced expiratory volume in one second were $0.947 \mathrm{mg} \cdot \mathrm{mL}^{-1}$ (GSEM 0.139) and $21.0 \mathrm{mg} \cdot \mathrm{mL}^{-1}$ (GSEM 0.112), respectively, which were not significantly different from those in the nonalcohol-sensitive group, which were $0.634 \mathrm{mg} \cdot \mathrm{mL}^{-1}$ (GSEM 0.115 ) and $31.7 \mathrm{mg} \cdot \mathrm{mL}^{-1}$ (GSEM 0.077 ), respectively. The ratio of airway responsiveness to acetaldehyde relative to methacholine (log PC20,acet/PC20,meth) was $1.345 \pm$ 0.093 (mean \pm SEM) in the alcohol-sensitive group, which was significantly different from the value of $1.699 \pm 0.059$ in the nonalcohol-sensitive group $(p=0.0025)$. A significant correlation was observed between PC20,meth and PC20, acet in both the alcoholsensitive group $(r=0.742, p=0.0115)$ and nonsensitive group $(r=0.882, p<0.0001)$.

In conclusion, the airways of asthmatic subjects with alcohol-induced bronchoconstriction have a selective hyperresponsiveness to acetaldehyde.
\end{abstract}

Eur Respir J 1999; 14: 19-22.

\begin{abstract}
*The Third Dept of Internal Medicine, ${ }^{+}$The Central Laboratory, and ${ }^{\#}$ Dept of Laboratory Medicine, Kanazawa University School of Medicine, Takara-machi, Kanazawa, Japan.
\end{abstract}

Correspondence: M. Fujimura, The Third Dept of Internal Medicine, Kanazawa University School of Medicine, 13-1 Takara-machi, Kanazawa 920, Japan. Fax: 81762344252

Keywords: Acetaldehyde

alcohol-induced bronchoconstriction

bronchial responsiveness

methacholine

Received: July 211998

Accepted after revision January 241999

This study was supported in a part by a Grant-in-aid from the Ministry of Education, Science and Culture (04807055) of the Japanese Government.
Acetaldehyde, a rapidly generated metabolite of ethanol, is thought to be a main factor of alcohol-induced bronchoconstriction. In alcohol-induced bronchoconstriction, which occurs in response to intrinsic histamine released by acetaldehyde and is a condition that occurs as the result of a genetic alteration in the metabolism of alcohol, findings indicate that: 1) blood acetaldehyde and histamine concentrations increase during alcohol-induced bronchoconstriction [1];2) inhaled acetaldehyde provokes bronchoconstriction indirectly via histamine release in guinea-pigs [2] and asthmatic subjects [3]; 3) the activity of aldehyde dehydrogenase (ALDH), which oxidizes acetaldehyde to acetate, is a major factor in determining exacerbations of asthma after alcohol intake [4]; 4) among asthmatic patients in Western societies, who usually do not develop bronchoconstriction in response to alcohol, severe asthmatic attacks follow alcohol intake in those who are chronically alcoholic and taking the ALDH inhibitor disulfiram as a component of alcohol-abstinence therapy [5]; and 5) terfenadine, a selective histamine $\mathrm{H}_{1}$ antagonist, completely inhibits alcohol-induced bronchoconstriction [6].

Although it has been demonstrated by the authors that inhaled acetaldehyde provokes bronchoconstriction in both asthmatic subjects with and without alcohol sensitivity [3, 7], it is unknown whether the airway response to acetaldehyde is augmented in subjects with alcohol-induced bronchoconstriction. It is therefore hypothesized that there is an increased airway responsiveness to acetaldehyde in asthmatic patients with alcohol-induced bronchoconstriction. In order to test this hypothesis, bronchial responsiveness to acetaldehyde and methacholine was compared in subjects with alcohol-induced bronchoconstriction and in a control group of asthmatic subjects without alcohol sensitivity.

\section{Subjects and methods}

\section{Subjects}

Ten alcohol-sensitive subjects (seven male, three female, aged 20-63 yrs), and 16 nonalcohol-sensitive asthmatic subjects (10 male, six female, aged 23-65 yrs), of whom nine were nonatopic and 17 were atopic, were studied (table 1). Each subject satisfied the American Thoracic Society definition of asthma [8]. Alcohol-induced bronchoconstriction was confirmed by a $>20 \%$ decrease in peak expiratory flow (PEF) after drinking all forms of alcoholic beverages such as beer, whisky, brandy, wine and Japanese sake. Atopy was defined by the presence of a positive serum specific immunoglobulin (Ig)E to at least two common aeroallergens: grass pollen, tree pollen, cat dander, dog hair, Dermatophagoides pteronyssinus and D. farinae. Each subject had not taken antihistamines, sodium cromoglycate, inhaled corticosteroids or oral corticosteroids for $\geq 1$ month prior to the study, and no subject had experienced an upper respiratory tract infection 
Table 1. - Subject characteristics

\begin{tabular}{|c|c|c|c|c|c|c|c|}
\hline $\begin{array}{l}\text { Subject } \\
\text { No. }\end{array}$ & $\begin{array}{l}\text { Age } \\
\text { yrs }\end{array}$ & Sex & Atopy & $\begin{array}{c}\text { FVC } \\
\% \text { pred }\end{array}$ & $\begin{array}{l}\text { FEV1 } \\
\% \text { pred }\end{array}$ & $\begin{array}{c}\mathrm{FEV} 1 / \mathrm{FVC} \\
\%\end{array}$ & Treatment \\
\hline \multicolumn{8}{|c|}{ Alcohol-sensitive asthmatic subjects } \\
\hline 1 & 26 & $\mathrm{M}$ & + & 115.1 & 104.1 & 83.5 & $\mathrm{Sa}$ \\
\hline 2 & 28 & M & - & 109.0 & 88.3 & 75.7 & $\mathrm{Sa}, \mathrm{Th}$ \\
\hline 3 & 31 & M & + & 112.3 & 83.5 & 69.7 & $\mathrm{Sa}, \mathrm{Th}$ \\
\hline 4 & 42 & M & + & 114.3 & 103.9 & 76.3 & $\mathrm{Sa}$ \\
\hline 5 & 36 & $\mathrm{~F}$ & - & 94.1 & 93.8 & 88.9 & $\mathrm{Sa}$ \\
\hline 6 & 57 & $\mathrm{M}$ & + & 94.3 & 83.3 & 72.9 & $\mathrm{Sa}, \mathrm{Th}$ \\
\hline 7 & 20 & M & + & 109.5 & 81.0 & 69.0 & $\mathrm{Sa}, \mathrm{Th}$ \\
\hline 8 & 26 & M & + & 102.6 & 88.0 & 77.6 & $\mathrm{Sa}$ \\
\hline 9 & 26 & $\mathrm{~F}$ & + & 107.7 & 89.6 & 82.4 & $\mathrm{Sa}$ \\
\hline 10 & 63 & $\mathrm{~F}$ & - & 103.3 & 103.2 & 79.4 & $\mathrm{Sa}, \mathrm{Th}$ \\
\hline Mean & 35.5 & & & 106.2 & 91.9 & 77.5 & \\
\hline SEM & 4.5 & & & 2.4 & 2.8 & 2.0 & \\
\hline \multicolumn{8}{|c|}{ Alcohol-tolerant asthmatic subjects } \\
\hline 1 & 24 & $\mathrm{M}$ & + & 113.7 & 87.0 & 71.5 & $\mathrm{Sa}$ \\
\hline 2 & 27 & M & + & 124.3 & 89.4 & 66.5 & $\mathrm{Sa}, \mathrm{Th}$ \\
\hline 3 & 45 & M & + & 114.5 & 91.2 & 70.3 & $\mathrm{Sa}, \mathrm{Th}$ \\
\hline 4 & 65 & M & - & 103.0 & 101.6 & 75.6 & $\mathrm{Sa}, \mathrm{Th}$ \\
\hline 5 & 39 & $\mathrm{~F}$ & + & 109.4 & 105.7 & 79.8 & $\mathrm{Sa}$ \\
\hline 6 & 23 & $\mathrm{~F}$ & - & 91.5 & 65.5 & 59.1 & $\mathrm{Sa}, \mathrm{Th}$ \\
\hline 7 & 57 & $\mathrm{~F}$ & - & 86.3 & 74.4 & 74.0 & Th \\
\hline 8 & 37 & M & + & 108.2 & 96.1 & 78.3 & $\mathrm{Sa}$ \\
\hline 9 & 52 & M & - & 83.5 & 78.4 & 80.1 & $\mathrm{Sa}$ \\
\hline 10 & 33 & $\mathrm{~F}$ & + & 120.9 & 100.7 & 76.6 & $\mathrm{Sa}, \mathrm{Th}$ \\
\hline 11 & 47 & $\mathrm{~F}$ & - & 97.4 & 106.8 & 77.5 & $\mathrm{Sa}, \mathrm{Th}$ \\
\hline 12 & 26 & M & + & 129.9 & 121.1 & 85.6 & $\mathrm{Sa}$ \\
\hline 13 & 32 & M & + & 108.5 & 92.2 & 71.4 & $\mathrm{Sa}, \mathrm{Th}$ \\
\hline 14 & 29 & M & + & 117.7 & 98.1 & 76.8 & $\mathrm{Sa}, \mathrm{Th}$ \\
\hline 15 & 23 & $\mathrm{~F}$ & + & 106.0 & 95.7 & 90.3 & $\mathrm{Sa}$ \\
\hline 16 & 52 & M & - & 90.3 & 67.9 & 80.5 & $\mathrm{Sa}, \mathrm{Th}$ \\
\hline Mean & 37.6 & & & 106.6 & 92.0 & 74.6 & \\
\hline SEM & 3.2 & & & 3.4 & 3.7 & 2.0 & \\
\hline
\end{tabular}

FVC: forced vital capacity; FEV1: forced expiratory volume in one second; M: male; F: female; Sa: salbutamol via metered-dose inhaler; Th: orally administered theophylline.

in the preceding month or during the study. Permitted medication, which remained unchanged during the study, included inhaled $\beta_{2}$-agonists and oral theophylline. This study was carried out when their symptoms were mild and stable. All medication was stopped at 13:00 h on the previous day to allow a washout time of at least $24 \mathrm{~h}$. The bronchial responsiveness to inhaled acetaldehyde or methacholine was then measured at 13:00 h on the test day. Informed consent was obtained from all subjects. This study was approved by the ethics committee of the authors university hospital.

\section{Bronchial responsiveness to inhaled acetaldehyde or methacholine}

Bronchoprovocation to acetaldehyde or methacholine was performed on two occasions 2 weeks apart, in a double-blind, randomized, crossover fashion. Acetaldehyde and methacholine were dissolved in physiological saline solution to make concentrations of $0.04,0.08,0.16,0.31$, $0.63,1.25,2.5,5,10,20,40$ and $80 \mathrm{mg} \cdot \mathrm{mL}^{-1}$. Saline and each solution were inhaled from a DeVilbiss 646 nebulizer (DeVilbiss Co., Somerset, PA, USA) operated by compressed air at $5 \mathrm{~L} \cdot \mathrm{min}^{-1}$. The nebulizer output was 0.14 $\mathrm{mL} \cdot \mathrm{min}^{-1}$. Saline was inhaled first for $2 \mathrm{~min}$ and forced expiratory volume in one second (FEV1) was measured. If the change in FEV1 from the baseline value was $\leq 10 \%$, inhalation of acetaldehyde or methacholine was started, and if the saline solution caused a change in FEV $1>10 \%$, the test was stopped or postponed. Acetaldehyde or methacholine was inhaled for $2 \mathrm{~min}$ by tidal mouth breathing and followed immediately by measurements of FEV1. Increasing concentrations of acetaldehyde or methacholine were inhaled until a fall of $\geq 20 \%$ in FEV1 occurred. FEV1 was measured three times and the highest FEV1 value of three attempts was recorded each time.

\section{Data analysis}

The provocative concentration of acetaldehyde ( $\mathrm{PC} 20$, acet) and methacholine (PC20,meth) causing a $20 \%$ fall in FEV1 were determined by linear interpolation from the log dose/response curve. PC20,meth and $\mathrm{PC}_{20}$,acet values were logarithmically transformed for analysis and reported as the geometric mean (geometric SEM (GSEM)). A 20\% fall in FEV1 was not obtained in one of 16 subjects without alcohol-induced bronchoconstriction at the highest concentration of acetaldehyde administered, and, therefore, a minimal estimate was obtained by calculating the cumulative PC20,acet on the next doubling concentration beyond the highest administered. The responsiveness of the airways to acetaldehyde relative to methacholine was 

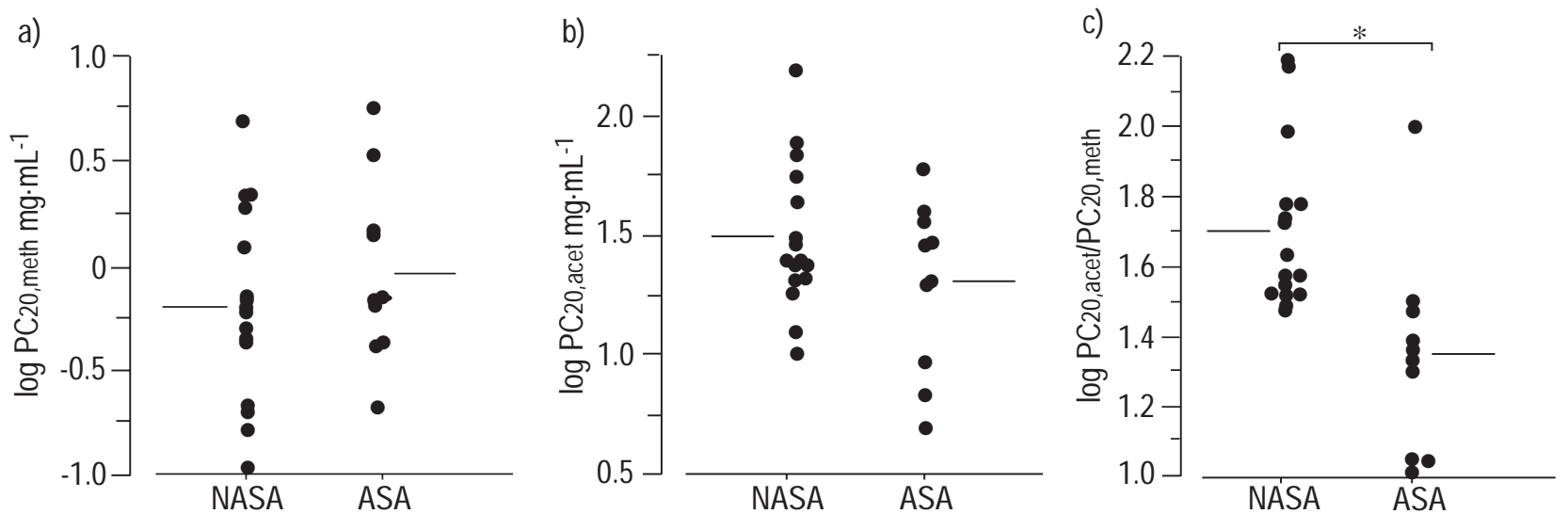

Fig. 1. - Bronchial responsiveness to methacholine (a) and acetaldehyde (b), and relative response of acetaldehyde to methacholine (c) in alcoholsensitive asthmatic (ASA) and nonalcohohol-sensitive asthmatic (NASA) subjects. Bars indicate geometric mean. PC20,meth, PC20,acet: provocative concentration of methacholine and acetaldehyde causing a $20 \%$ fall in forced expiratory volume in one second, respectively. $*$ : $\mathrm{p}=0.0025$.

calculated as $\log (\mathrm{PC} 20$,acet/PC20,meth) and reported as the mean \pm SEM. Variation between the unpaired values was statistically analysed using the unpaired Student's t-test. Correlations were obtained using Pearson's correlation coefficient. Significance was based on a $95 \%$ confidence level $(\mathrm{p}<0.05)$.

\section{Results}

The geometric means of $\mathrm{PC} 20$,meth and $\mathrm{PC} 20$,acet in the alcohol-sensitive group were $0.947 \mathrm{mg} \cdot \mathrm{mL}^{-1}$ (GSEM 0.139) and $21.0 \mathrm{mg} \cdot \mathrm{mL}^{-1}$ (GSEM 0.112 ), respectively, which were not significantly different from those in the nonalcoholsensitive group, which were $0.634 \mathrm{mg} \cdot \mathrm{mL}^{-1}$ (GSEM 0.115 ) $(\mathrm{p}=0.35)$ and $31.7 \mathrm{mg} \cdot \mathrm{mL}^{-1}$ (GSEM 0.077) $(\mathrm{p}=0.18)$, respectively (fig. 1). The responsiveness of the airways to acetaldehyde relative to methacholine was $1.345 \pm 0.093$ in the

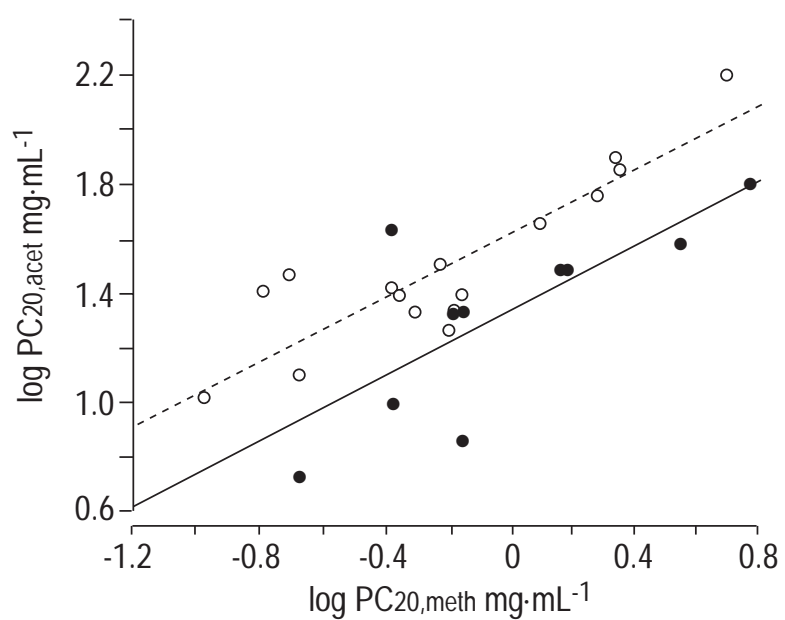

Fig. 2. - Relationship between bronchial responsiveness to methacholine and acetaldehyde in alcohol-sensitive asthmatic $(\boldsymbol{O})$ and nonalcohol-sensitive asthmatic $(\bigcirc)$ subjects. The regression lines for nonalcohol-sensitive asthmatics (- - -) and alcohol-sensitive asthmatics $(-)$ subjects are shown. $\mathrm{PC} 20$, meth and $\mathrm{PC} 20$,acet: provocative concentration of methacholine and acetaldehyde causing a $20 \%$ fall in forced expiratory volume in one second, respectively. A significant correlation was observed between $\mathrm{PC} 20$, meth and PC20,acet in both the alcohol-sensitive group $(\mathrm{r}=0.742, \mathrm{p}=0.0115)$ and nonalcohol-sensitive group $(\mathrm{r}=0.882, \mathrm{p}<0.0001)$ alcohol-sensitive group, which was significantly different from the nonalcohol-sensitive group (1.699 \pm 0.059$)$ $(\mathrm{p}=0.0025)$ (fig. 1). A significant correlation was observed between PC20,meth and PC20,acet in both the alcoholsensitive group $(\mathrm{r}=0.742, \mathrm{p}=0.0115)$ and nonsensitive group ( $\mathrm{r}=0.882, \mathrm{p}<0.0001)$ (fig. 2 ). There was no significant difference between the responsiveness of the airways to acetaldehyde compared to methacholine between atopic and nonatopic subjects in the nonalcohol-sensitive group.

\section{Discussion}

In this study, the bronchial responsiveness to acetaldehyde and methacholine in asthmatic subjects with and without alcohol-induced bronchoconstriction was investigated. The results showed that bronchial responsiveness to acetaldehyde relative to methacholine was augmented in asthmatic subjects with alcohol-induced bronchoconstriction when compared to asthmatic subjects who were tolerant to alcohol, and that a positive correlation between PC20,meth and PC20,acet was statistically significant in both the alcohol-sensitive group and nonsensitive group. Since the authors [3] have already reported that inhalation of acetaldehyde by the same method causes no significant bronchoconstriction in healthy nonasthmatic subjects, no control subject without asthma participated in this study.

Inhaled acetaldehyde causes bronchoconstriction indirectly via endogenously released histamine in guinea-pigs [2] and asthmatic subjects [3]. Although the origin of the histamine released by acetaldehyde in asthmatic airways is not clear, acetaldehyde causes dose-dependent histamine release from the leukocytes of asthmatic subjects in vitro [1]. At present, the mechanism responsible for the increased acetaldehyde responsiveness of asthmatic airways in alcohol-sensitive subjects is unclear, but possibilities include the increased releasability of histamine releasers such as leukocytes and an inability to metabolize acetaldehyde. SHImoda et al. [1] reported that leukocyte histamine release induced by acetaldehyde was not different between alcohol-sensitive and nonalcohol-sensitive asthmatic patients, making it unlikely that the change in histamine releasability plays an important role in the 
selective hyperresponsiveness to acetaldehyde in subjects with alcohol-induced bronchoconstriction.

Ethanol is oxidized to acetaldehyde, which in turn is oxidized to acetate, mainly by ALDH, which consists of two main isozymes with low and high Michaelis-Menten constant $(K \mathrm{~m}$; the substrate concentration at which an enzyme-catalysed reaction proceeds at half its maximum velocity) for aldehyde [9-11]. Approximately 50\% of Japanese people lack the low $K \mathrm{~m}$ enzyme (ALDH type 2 (ALDH2)), and show an elevation of serum acetaldehyde concentration due to their inability to metabolize acetaldehyde [12-14], which is a major factor in determining exacerbations of asthma after alcohol intake [4]. For example, it has been reported that a significant bronchoconstriction $(>20 \%$ decrease in FEV1) was observed after oral ethanol challenge in three of $16(19 \%)$ Japanese asthmatic patients with a normal homozygous ALDH2 genotype (normal ALDH2 activity), 10 of 14 (71\%) Japanese asthmatics with a mutant heterozygous ALDH2 genotype (low ALDH2 activity), and two of two (100\%) Japanese asthmatics with a mutant homozygous ALDH2 genotype (no ALDH2 activity) [4]. Since ALDH2 is reported to be expressed in human lungs $[10,15]$ and the genetic polymorphism at the ALDH2 gene locus occurs in Oriental populations, it is intriguing to predict that the pulmonary ethanol-metabolizing capabilities may vary in individuals with different genetic phenotypes. Although the lung ALDH2 activity was not examined in the present study, it is possible that the lung ALDH2 activity plays an important role in relative bronchial hyperresponsiveness to acetaldehyde in alcohol-sensitive asthmatics. However, further studies are required to draw a conclusion.

In summary, this study has demonstrated an increased airway responsiveness to acetaldehyde relative to methacholine in asthmatic subjects with alcohol-induced bronchoconstriction. It is believed that this is the first report suggesting bronchial hyperresponsiveness to acetaldehyde in alcohol-sensitive asthmatic subjects.

\section{References}

1. Shimoda T, Kohno S, Takao A, et al. Investigation of the mechanism of alcohol-induced bronchial asthma. $J$ Allergy Clin Immunol 1996; 97: 74-84.

2. Myou S, Fujimura M, Bando T, Saito M, Matsuda T. Aerosolized acetaldehyde, but not ethanol, induces histamine-mediated bronchoconstriction in guinea pigs. Clin Exp Allergy 1994; 24: 140-143.
3. Myou S, Fujimura M, Nishi K, Ohka T, Matsuda T. Aerosolized acetaldehyde induces histamine-mediated bronchoconstriction in asthmatics. Am Rev Respir Dis 1993; 148: 940-943.

4. Takao A, Shimoda T, Kohno S, Asai S, Harda S. Correlation between alcohol-induced asthma and acetaldehyde dehydrogenase-2 genotype. J Allergy Clin Immunol 1998; 101: 576-580.

5. Zapata E, Orwin A. Severe hypertension and bronchospasm during disulfiram-ethanol test reaction. $B M J$ 1992; 305: 870 .

6. Myou S, Fujimura M, Nishi K, Ohka T, Matsuda T. Inhibitory effect of terfenadine, a selective $\mathrm{H}_{1}$ histamine antagonist, on alcoholic beverage-induced bronchoconconstriction in asthmatic patients. Eur Respir J 1995; 8: 619-623.

7. Myou S, Fujimura M, Kamio Y, Bando T, Nakatsumi Y, Matsuda T. Repeated inhalation challenge with exogenous and endogenous histamine released by acetaldehyde inhalation in asthmatic patients. Am J Respir Crit Care Med 1995; 152: 456-460.

8. American Thoracic Society. Standard for diagnosis and care of patients with chronic obstructive pulmonary disease (COPD) and asthma. Am Rev Respir Dis 1987; 136: 225-244.

9. Greenfild NJ, Pietruszko R. Two aldehyde dehydrogenase from human liver. Isolation via affinity chromatography and characterization of the isozymes. Biochem Biophys Acta 1977; 483: 35-45.

10. Harada S, Agarwal DP, Goedde HW. Electrophoretic and biochemical studies of human aldehyde dehydrogenase isozymes in various tissues. Life Sci 1980; 26: 17731780.

11. Koivula T. Subcellular distribution and characterization of human liver aldehyde dehydrogenase fractions. Life Sci 1975; 16: 1563-1570.

12. Agarwal DP, Harada S, Goedde HW. Racial differences in biological sensitivity to ethanol. The role of alcohol dehydrogenase isozymes. Alc Clin Exp Res 1981; 5: 12-16.

13. Goedde HW. Liver alcohol dehydrogenase and aldehyde debydrogenase in the Japanese: isozyme variation and its possible role in alcohol intoxication. Am J Hum Genet 1980; 32: 8-15.

14. Harada S, Agarwal DP, Goedde HW. Isozymes of alcohol dehydrogenase and their role in alcohol sensitivity. $A d v$ Exp Med Biol 1980; 132: 31-39.

15. Smith M, Hopkinson DA, Harris H. Developmental changes and polymorphism in human alcohol dehydrogenase. Ann Hum Genet 1971; 34: 251-271. 